\title{
EDITORIAL
}

Lúcia Vidal Soares [htrps://orid.org/0000-0002-0431-4184]

Instituto Politécnico de Lisboa, Escola Superior de Educação, Lisboa, Portugal

Xeusa Maria Oliveira Barbosa Bastos [htrp://orid.org/0000-0001-5529-4606]

Pontifícia Universidade Católica de São Paulo, São Paulo, SP, Brasil

Regina Felena Pires de Brito [htpp//orid.org/0000-0002-0634-8572]

Universidade Presbiteriana Mackenzie, São Paulo, SP, Brasil

Maria Inês Batista Campos [htrps://orid.org/0000-0003-0004-9923]

Universidade de São Paulo, São Paulo, SP, Brasil

\section{Cartografia(s) da (s) Lusofonia (s)}

\begin{abstract}
A Língua, à velha maneira de Brecht, retira passividade às margens e intimida o rio a ser plural; o rio que corria estreito e manso, agora caudaloso faz uso de uma rebeldia saudável. Porque a natureza da água (da cultura) é mover-se, descendo o vale ou trepando a montanha, em luta de vaivém ternurento com a vã pressão dos homens. E se a margem toca o rio, o rio beija a margem numa dúvida aquática sem limite de exactidão.
\end{abstract}

ONDJAKI: 2004, p. 344.

"Acho importante questionar a ideia da lusofonia. E perceber que o conceito é plural: existem lusofonias. A ideia da comunidade lusófona é uma construção que corresponde a interesses políticos particulares. Os criadores culturais devem ser capazes de questionar esse modelo único que nos é proposto" - assim afirma Mia Couto, em entrevista ao jornal O Estado de S. Paulo, motivada pela participação do afamado escritor moçambicano na 21 a Bienal do Livro de São Paulo, ao ser 
Linha D'Água (Online), São Paulo, v. 32, n. 2, p. 1-10, maio-ago. 2019

indagado sobre o que considerava essencial discutir no debate sobre a lusofonia, proposto para aquela edição da Bienal (BRITO: 2015, p. 298).

Por seu lado, José Eduardo Agualusa, reconhecido escritor angolano, propõe que lusofonia seja encarada como "um daqueles conceitos elásticos em que cada qual entende à sua maneira” (2018, p. 43). Não deixa, no entanto, de definir aquilo que designa por lusofonia horizontal: "um espaço de língua portuguesa em que todas as partes participam de forma livre, em situação de igualdade, sem dominados nem dominadores (2018, p. 46). Já em 2003, no Suplemento PÚBLICA do Jornal Público de 27 de julho, esse autor referia que

Muitas das pessoas que se opõem à lusofonia, acusando os portugueses de ocultas intenções neocoloniais, não se opõem ao conceito de lusofonia, ainda que suponham tal coisa, e sim, tão somente, à expressão. (...) Talvez valha a pena pensar em conjunto numa outra expressão. Algo como Irmandade. Fraternidade; ou melhor, como sugeriu recentemente o escritor timorense Luís Cardoso, durante a Festa da Lusofonia, em Lisboa, a Fraternidade da Fala.

Vem daí a inspiração para o exercício reflexivo que se propõe ao tratar da(s) Cartografia(s) da(s) Lusofonia(s), porque, em essência, na perspectiva que adotamos, a Lusofonia é fundamentalmente plural. Assim é que tratar de lusofonia(s) supõe debater aspectos que destacam o papel da língua portuguesa como instrumento construtor de identidades múltiplas (linguística, cultural e social) do sujeito nos países de oficialidade lusófona - Angola, Brasil, Cabo Verde, Guiné-Bissau, Guiné -Equatorial ${ }^{1}$, Moçambique, Portugal, São Tomé e Príncipe e Timor-Leste - em outros espaços de presença significativa de comunidades lusofalantes da diáspora, além de regiões como Galiza e Macau, por exemplo.

Sabemos que a cultura em que estamos inseridos e a língua que falamos referem-se às nossas experiências; expressamos fatos, ideias ou acontecimentos que podem ser comunicados exatamente por se referirem a um 'estoque' de conhecimentos sobre o mundo e que pode ser compartilhado com outras pessoas, pois, segundo Kramsch:

1 Este país só recentemente passou a integrar a CPLP (2014) não tendo ainda uma política linguística implementada de integração da língua portuguesa. 
As palavras também refletem as atitudes e crenças do autor, seu ponto de vista que é também dos outros e, portanto, "a língua reflete a realidade cultural” e mais “a língua também incorpora a realidade cultural”, através de seus aspectos verbais e não-verbais. Os membros de uma comunidade ou grupo social expressam experiências como também criam experiências através das linguagens verbais e nãoverbais. Podemos acrescentar que a realidade cultural é simbolizada pela língua, pois os interlocutores se identificam por meio do uso da língua que é considerada o símbolo da identidade cultural. (1998, p. 3 - tradução nossa).

Assim, a língua considerada como símbolo da identidade cultural, propicia a compreensão aos falantes de cada um dos países lusófonos, não somente do significado isolado das palavras, mas para a construção da interpretação dos acontecimentos. Temos também a necessidade de compreender e respeitar as especificidades de cada contexto ideológico-cultural e situacional da comunidade lusófona.

Estando a referir-nos a contextos essencialmente pós-coloniais, importa relembrar que a língua pode atrelar-se à responsabilidade do processo colonizador, durante o período de colonização, mas, após a independência, são os novos dirigentes que fazem a escolha das novas políticas linguísticas a seguir. Trata-se, no nosso caso, de países, mormente, multilíngues e multiculturais, esperar-se-ia por isso que as línguas autóctones, ou, pelo menos, algumas delas tomassem o lugar que lhes é devido, mas raramente tal acontece, mantendo-se a língua do colonizador (veja-se, a título de exemplo, a atual situação da América latina) (cf. SOARES, 2014). Ora a construção dessas identidades plurilíngues tem implicações de várias ordens (políticas, éticas e sociais). Verifica-se, igualmente, que a mundialização e a globalização colocam novos desafios do ponto de vista da coesão social e da integração, na medida em que procuram unificar o que era múltiplo.

Constata-se, por outro lado, que quando ocorre esta opção de revalorizar as línguas locais, mantendo a língua oficial estrangeira, tal decisão tem feito despertar reivindicações identitárias (cf. SAGARA, 2008; VAN DEN AVENNE, 2012), ainda que Fettes (2003, citado por García 2007) "reconheça que, num mundo fortemente globalizado, as políticas linguísticas que uniam a língua à identidade e que funcionaram no decorrer do séc. XX, já não resultam (SOARES: 2014, p. 77). Embora Byram (1992) nos acautele para o facto de a língua e as suas variantes serem manifestações abertas da identidade (linguística, cultural e social) com as 
Linha D'Água (Online), São Paulo, v. 32, n. 2, p. 1-10, maio-ago. 2019

quais nos confrontamos na vida cotidiana. Assim, cada falante utiliza, mais ou menos conscientemente, uma variante linguística para revelar a sua identidade social, por vezes, ajustando-a em função da situação e dos interesses. Constata-se que, "em contexto pós-colonial e de globalização, no séc. XXI, vai-se alcançando uma visão "heteroglóssica", em que a relação entre língua e cultura não é unidirecional, mas no qual, a língua vai contribuindo para a construção de identidades múltiplas" (SOARES: 2014, p. 141).

Pelas razões acima referidas, parece-nos importante pugnar pela construção de uma identidade lusófona, proposta por Brito (2013, p. 123) e que abrangeria a capacidade de "respeitar as experiências particulares, os valores distintos, a especificidade cultural e suas aproximações, o modo próprio de vivenciar a realidade e a visão de mundo que cada comunidade do universo lusófono fixa na variedade do português". E aqui temos de relembrar que, no mundo atual, a integração numa comunidade mais vasta, onde o elemento aglutinador é a língua se torna fundamental. A junção de "cada comunidade do universo lusófono" acabou por dar origem à Comunidade de Países de Língua Portuguesa (CPLP), constituída em 1996. Trata-se de

[...] um novo projecto político cujo fundamento é a Língua Portuguesa, vínculo histórico e património comum dos Oito [à época] - que constituem um espaço geograficamente descontínuo, mas identificado pelo idioma comum [...]. A CPLP tem como objectivos gerais a concertação política e a cooperação nos domínios social, cultural e económico. (CPLP, 1996, p. 14)

Amélia Mingas na abertura do Simpósio Internacional "Interpenetração da Língua e Culturas de/em Língua Portuguesa na CPLP, realizado pelo IILP/AULP, em S. Vicente, Cabo Verde, em 2010, afirmou, numa posterior sintonia com Brito:

Parece-nos inquestionável a verificação histórica de que a Comunidade de Países de Língua Portuguesa resulta da contribuição de várias realidades sociológicas, linguísticas, políticas e culturais, num esforço de identificação de valores que não ponham em causa a identidade própria de cada um dos Estados integrantes (MINGAS, 2010, p. 13). 
Linha D'Água (Online), São Paulo, v. 32, n. 2, p. 1-10, maio-ago. 2019

Reconheceu ainda que

A CPLP se instituiu no esteio de uma língua de identificação comum, mas não é menos certo que essa identificação comum se vai definindo com as impressões digitais das várias matizes particulares e específicas das partes, que o seu enriquecimento será tanto maior quanto mais livres e criadores forem os impulsos dessas matizes e que a universalidade deste valor - o uso da língua portuguesa-está ainda longe de ser alcançada em muitos dos nossos países" (CPLP, 1996, p. 15)

No entanto, o potencial cultural e económico do espaço lusófono não pode ser descorado, tendo mesmo suscitado um grande interesse pela língua a Oriente (leva a que a língua esteja em grande expansão, por exemplo, na República Popular da China).

Convém ressalvar que CPLP e Lusofonia(s) não são coincidentes, uma vez que a comunidade integra Estados/Nações e não, como atrás referimos, "espaços de presença significativa de comunidades lusofalantes da diáspora”.

Além disso, o estudo da lusofonia (ou das lusofonias) preocupa-se com o reconhecimento das diferentes normas do português, com análises das políticas linguísticas desenvolvidas em cada espaço, com processos voltados para a difusão da língua portuguesa em contextos multilíngues e, ainda, com reflexões sobre a internacionalização do português no século XXI.

Naturalmente, do ponto de vista dos povos colonizados, é difícil dissociar o passado histórico colonial do sentido que a palavra Lusofonia ${ }^{2}$ traz nos dicionários: no plano etimológico, o substantivo abstrato Lusofonia liga-se à "Lusitânia", província romana pertencente à Hispânia, habitada pelos Lusitanos: a forma luso, do latim lusu, remete a lusitano, português, relativo a Portugal e a forma (de origem grega) fon relaciona-se a som, voz, palavra, língua. É desta via, portanto, que se retira seu conceito mais evidente e divulgado: o de abranger os países de língua portuguesa ou seja, "o espaço simbólico linguístico e, sobretudo, cultural no âmbito da língua portuguesa e das suas variedades linguísticas”(BRITO: 2010, p. 177).

2 Ver Brito e Bastos (2007), que sugerem a necessidade de uma ressemantização do termo "lusofonia", desvinculando-o da perspectiva etimológica. 
Linha D'Água (Online), São Paulo, v. 32, n. 2, p. 1-10, maio-ago. 2019

No entanto, como escreve Ivo Castro "a língua a que chamamos portuguesa nasceu na Galiza e numa região minhoto-duriense que, na época, também era galega; a língua já existia, portanto, quando o país foi desenhado a sul do rio Douro e transplantou-se [...]. Em Lisboa, como em S. Paulo e em Maputo é uma língua que veio de fora" (2004, p. 279). Numa conceituação um pouco mais alargada, costumase, então, aplicar o termo "lusófono" aos indivíduos que têm em comum a Língua Portuguesa e que partilham, além dela, múltiplos elementos culturais e históricos.

A afirmação da lusofonia deve decorrer, essencialmente da riqueza e da inspiração dos lusófonos, das diásporas dispersa pelos quatro cantos do mundo e dos lusófilos, apaixonados pela língua portuguesa e pela diversidade das culturas lusófonas. Parece ter chegado o momento para que os países de língua oficial portuguesa e as diversas comunidades lusófonas possam evidenciar o respeito pelas culturas que se conjugam no/ conjugadas no plural, por meio de uma geografia que é estrategicamente pertinente em relação à história e aos desafios contemporâneos. A lusofonia tem de ter em si mesma valores e uma universalidade que percorram/ atravessem o tempo e o espaço, e se projete no futuro, ou como diria Ondjaki "devolvendo à Língua uma faceta adequada para enfrentar futuros “(2004; p. 345).

Com efeito, o termo lusófono se apresenta a partir do contato vivo e constante de culturas e línguas diversas presentes na(s) cartografia(s) da lusofoni(a). Nesse desenho é que se inserem, dialogicamnete, os textos que compõem este número da Revista Linha D'Água, que se abre com artigo O Instituto Internacional da Lingua Portuguesa da CPLP Aspectos da gestão de uma organização político-linguística original, de Gilvan Muller Oliveira, que apresenta uma análise do funcionamento e das realizações e das suas limitações no âmbito da promoção da língua portuguesa como língua pluricêntrica de quatro momentos de vida da IILP, periodizados em 1. Concepção; 2. Instalação; 3. Consolidação e 4. Expansão.

Em $A$ promoção do português como língua global no século XXI - um cenário a partir do Brasil, a pesquisadora Edleise Mendes discute o desenvolvimento e a expansão das políticas de promoção, projeção e difusão do português no mundo, destacando o Brasil no exterior, sobretudo no âmbito institucional; analisa problemas e desafios enfrentados e comenta iniciativas já realizadas e outras em curso, 
Linha D'Água (Online), São Paulo, v. 32, n. 2, p. 1-10, maio-ago. 2019

tecendo considerações sobre os problemas e as perspectivas relativas à questão, no cenário de promoção das línguas no século XXI.

O terceiro artigo, de Luísa Antunes Paolinelli, intitulado O incipit na novelistica histórica portuguesa e brasileira: Alexandre Herculano, Almeida Garrett e José de Alencar, volta-se para a questão literária lusófona. A autora aborda o incipit como partida para um lugar, como origem de um itinerário narrativo desconhecido, apontando a ironia romântica de Alencar, ao fazer da descrição incipitaria uma verdadeira instituição agregando em si objetivos ligados à construção da narrativa identitária.

Lucia Vidal Soares, no quarto artigo do volume, O português no contexto multilingue timorense - entre ficar e partir, discorre sobre a situação linguística de Timor-Leste, abordando as relações entre o português e as restantes línguas que circulam naquele território, tanto do ponto de vista da política linguística, quanto no âmbito das representações dos sujeitos.

Expressões idiomáticas são o tema de Flavio Biasutti Valadares que aborda, no quinto artigo - Interconexões na integração lusófona -, as possibilidades de interconexão no espaço lusófono, a partir da ideia de construção identitária por meio do recurso às expressões idiomáticas, destacando-se a integração no mundo da lusofonia, com o objetivo de discutir a questão da identidade lusófona em relação aos idiomatismos comuns em diversos ambientes de produção, ressaltando tal espaço como propício à discussão de interculturalidade.

Em Encenaçôes da escrita nos textos de Adília Lopes, sexto artigo desta obra, Olga Kempinska comenta sobre as funções estética e éticas nos poemas e nas narrativas-fragmentos de Adília Lopes que garante se tratar de um intenso convívio com a tessitura da morte e de um significativo deslocamento de sua representação do domínio consagrado pela tradição - o das flores, dos ossos e das conchas - para o âmbito dos materiais da escrita.

Vicente Paulino é o autor do sétimo artigo, intitulado Cartografia da lusofonia de lingua portuguesa no mundo e em Timor-Leste, em que o estudioso reflete sobre os discursos políticos e os discursos dos cooperantes que ofereceram, e ainda oferecem, a sua prestação de serviço ao ensino timorense em/na língua portuguesa, numa perspectiva de consolidação da língua portuguesa no contexto 
Linha D'Água (Online), São Paulo, v. 32, n. 2, p. 1-10, maio-ago. 2019

leste-timorense, realçando os conceitos de "lusofonia" e de "consciência nacional" em torno do patrimônio imaterial, que é a língua portuguesa.

Fecha este volume, o artigo Consciência lusófona em "Uma politica do idioma", de Celso Cunha, em que Sônia Maria Nogueira, Patrícia Leite Di Iório eWemylla de Jesus Almeida analisam do ponto de vista historiográfico a proposta de política do idioma apresentada por Celso Cunha em conferência, no Ministério da Educação e Cultura, em 1963, procurando uma compreensão do contexto político-linguístico-educacional em que o discurso é proferido e, ainda, buscando as concepções de língua e de política do idioma que estão imanentes no texto.

$\mathrm{Na}$ seção Resenha, a obra destacada intitula-se Contribuições de pesquisas acadêmicas para o campo do ensino de português como lingua não materna. A resenhista, Maria do Carmo Ribeiro, trata dessa coletânea de capítulos situados na área de ensino de Português como Língua Estrangeira, escritos por professores e pesquisadores reconhecidos e atuantes no meio acadêmico com o objetivo de mostrar questões teóricas e metodológicas nesse segmento importante de difusão do português.

Com este conjunto de textos, Linha d'Água convida o leitor a viajar conosco por terras brasileiras, portuguesas, africanas e ilhas além-mar, na esperança de que os estudos provoquem novas pesquisas.

A publicação deste número contou com o auxílio do Departamento de Letras Clássicas e Vernáculas, DLCV da Faculdade de Filosofia, Letras e Ciências Humanas e o Programa de Apoio às Publicações Científicas Periódicas da Universidade de São Paulo/SIBi, a quem agradecemos por permitir a manutenção de Linha d'Água, indexada na Web of Science, base de dados de citações científicas do Institute for Scientific Information, mantido pela Clarivate Analytics, nas áreas de Ciências Sociais, Artes e Humanidades.

O processo de submissão e seleção dos artigos da revista conta com pareceristas do Conselho editorial e ad hoc, procedimento que torna este número de alta qualidade e com um grupo de revisores de língua portuguesa. Conta também com a professora Roseli Serra da Universidade Católica de Pernambuco, o que permite manter a excelência da revisão de Linha d'Água. Com todos os envolvidos, a revista torna-se um espaço aberto a publicações ligadas aos estudos de língua portuguesa, 
Linha D’Água (Online), São Paulo, v. 32, n. 2, p. 1-10, maio-ago. 2019

aos estudos linguístico-discursivos e sua relação com o ensino, mantendo um diálogo constante com as pesquisas desenvolvidas no Brasil e no exterior.

Com esse número da revista, o Conselho Editorial busca a internacionalização do periódico com artigos de autores de diferentes universidades brasileiras e estrangeiras, procurando responder às exigências da Universidade de São Paulo e das agências internacionais.

\section{Referências}

AGUALUSA, J.E. O Paraiso e outros infernos. Lisboa: Quetzal, 2018.

BRITO, R. P. de. Temas para a compreensão do atual quadro linguístico de Timor-Leste. In: A. D. Pereira (Ed.), Ciências \& Letras - Ásia: história e cultura (vol. 48, p. 175-194). Porto Alegre: Faculdade Portalegrense, 2010.

Lingua e identidade no universo da lusofonia: aspectos de Timor-Leste e Moçambique. São Paulo: Terracota, 2013.

À mistura estão as pessoas: lusofonia, política linguística e internacionalização. In: Lusofonia e interculturalidade. Promessa e travessia. Moisés Martins (Coor.). Braga: Universidade do Minho e Húmus, 2015.

BRITO, R.P de. e BASTOS, N. B. Dimensão semântica e perspectivas do real: comentários em torno do conceito de lusofonia. In Sousa, H. e Martins, M.L. (Org.), Comunicaşão e Lusofonia (p. 65-78). Porto: Campo das Letras, 2007.

BYRAM, M. Culture et éducation en langue étrangère, Paris: Hatier, 2010.

CASTRO, I. Introduçao à história do português. Lisboa: Colibri, 2004.

CPLP. (1996) Comunidade dos Países de Língua Portuguesa. Estatutos e Objectivos. Disponível em http://www.cplp.org. Acesso em 10/05/2019.

GARCÍA, O. Lenguas e identidades en mundos hispanohablantes. Desde una posición plurilingüe y minoritaria. In M. Lacorte (ed.), Lingüistica aplicada del español (p. 377-400). Madrid: Arco, 2007. 
Linha D'Água (Online), São Paulo, v. 32, n. 2, p. 1-10, maio-ago. 2019

KRAMSCH, C. Language and culture. Oxford University Press, 1998.

MINGAS, A. IILP/AULP. Abertura. Atas do Simpósio Internacional Interpenetração da Lingua e Culturas delem Lingua Portuguesa na CPLP. Mindelo: IILP/AULP, 2010.

ONDJAKI. Outras margens da mesma língua in A Lingua Portuguesa: Presente e Futuro. Lisboa: Fundação Calouste Gulbenkian, 2004.

SOARES, L.V. Linguas em Timor-Leste: que gestão escolar do plurilinguismo?, tese de doutoramento apresentada no Departamento de Educação da Universidade de Aveiro, 2014. Disponível em: https://www.academia.edu /6461354/L\%C3\%Adnguas em TimorLeste_que_gest\%C3\%A3o_escolar_do_plurilinguismo. Acesso em 18 jun. 2019.

SOARES, L. V. e BRANCO, L. A Lingua Portuguesa como traço de união entre culturas. Porto: Colóquios da Lusofonia, 2001.

São Paulo, agosto de 2019. 